\title{
Perilipin 5 promotes hepatic steatosis in dairy cows through increasing lipid synthesis and decreasing very low density lipoprotein assembly
}

\author{
Hongdou Jia, ${ }^{1 *}$ Xiaobing Li, ${ }^{1 *}$ Guowen Liu, ${ }^{1}$ Juan J. Loor, ${ }^{2}$ Ryan Bucktrout, ${ }^{2}$ Xudong Sun, ${ }^{1}$ Guojin Li, ${ }^{1}$ \\ Xin Shu, ${ }^{1}$ Jihong Dong, ${ }^{1}$ Yazhe Wang, ${ }^{1}$ Rankun Zuo, ${ }^{3}$ Zhe Wang, ${ }^{1}$ and Xinwei $\mathrm{Li}^{1} \dagger$ \\ ${ }^{1}$ Key Laboratory of Zoonosis, Ministry of Education, College of Veterinary Medicine, Jilin University, 5333 Xi'an Road, Changchun, 130062, Jilin, \\ China \\ ${ }^{2}$ Mammalian NutriPhysioGenomics, Department of Animal Sciences and Division of Nutritional Sciences, University of Illinois, Urbana 61801 \\ ${ }^{3}$ College of Veterinary Medicine, Qingdao Agriculture University, Qingdao, 266109, Shandong, China
}

\section{ABSTRACT}

Fatty liver is a common metabolic disorder in dairy cows during the transition period. Perilipin 5 (PLIN5), a lipid droplet coat protein, plays important roles in the development of hepatic steatosis in mice and humans. Whether PLIN5 plays a role in the development of fatty liver in dairy cows is unknown. An in vivo study consisting of 10 healthy and 10 cows with fatty liver was performed to harvest liver tissue and blood samples. In addition, hepatocytes isolated from calves were infected with PLIN5 overexpression adenovirus for $48 \mathrm{~h}$; treated with $0,0.6,1.2$, or $2.4 \mathrm{~m} M$ nonesterified fatty acids (NEFA) for $24 \mathrm{~h}$; or infected with PLIN5 silencing adenovirus for $48 \mathrm{~h}$ and then treated with 1.2 $\mathrm{m} M$ NEFA for $24 \mathrm{~h}$. Serum concentrations of NEFA and $\beta$-hydroxybutyrate were greater in cows with fatty liver. Milk production and plasma glucose concentrations were lower in cows with fatty liver. The results revealed that PLIN5 is highly expressed in steatotic liver and localized to lipid droplets. The abundance of fatty acid and triacylglycerol (TAG) synthesis-related proteins including sterol regulatory element binding protein-1c, fatty acid synthase, acetyl-coA carboxylase 1, diacylglycerol acyltransferase 1, and diacylglycerol acyltransferase 2 was greater in the liver of cows with fatty liver. In contrast, the abundance of microsomal triglyceride transfer protein (MTP), apolipoprotein B100, and apolipoprotein E was lower in the liver of cows with fatty liver. Consequently, cows with fatty liver exhibited severe hepatic TAG accumulation and lower blood concentration of very low density lipoprotein apolipoprotein B (VLDL-ApoB). Overexpression of PLIN5 and exogenous NEFA in cultured hepatocytes

Received June 14, 2018.

Accepted September 24, 2018.

*These authors contributed equally to this study.

†Corresponding author: lixinwei100@126.com increased the abundance of sterol regulatory element binding protein-1, fatty acid synthase, acetyl-coA carboxylase 1, diacylglycerol acyltransferase 1, and diacylglycerol acyltransferase 2 but decreased the abundance of microsomal triglyceride transfer protein, apolipoprotein B100, and apolipoprotein E, which promoted TAG synthesis and inhibited VLDL-ApoB assembly, inducing lipid accumulation. Importantly, knockdown of PLIN5 attenuated the upregulation of TAG synthesis and downregulation of VLDL-ApoB assembly induced by NEFA. Overall, these data suggest that NEFA activate PLIN5, leading to TAG accumulation and inhibition of VLDL assembly. As such, these mechanisms explain in part the development of hepatic steatosis in dairy cows. Key words: perilipin 5, fatty liver, dairy cow, fatty acid

\section{INTRODUCTION}

Fatty liver is an important metabolic disorder during the transition period (Goff and Horst, 1997; Jorritsma et al., 2001). Estimates indicate that during the first 4 wk after parturition $50 \%$ of cows or more suffer different degrees of triacylglycerol (TAG) accumulation in the liver (Jorritsma et al., 2000). Body fat mobilization due to negative energy balance (NEB) and the resulting increase in plasma concentration of fatty acids (Gross et al., 2011; Wathes et al., 2011; Contreras et al., 2016) early postpartum are important causes of fatty liver. The phenotype is characterized by accumulation of TAG in hepatocytes (Drackley, 1999), partly due to excessive fatty acid infiltration into liver and the inherently slow rate of hepatic very low density lipoprotein (VLDL) secretion (Pullen et al., 1990). Clearly, fatty liver occurs when there is an imbalance between lipid availability and lipid disposal in the liver.

Most TAG are stored in the form of lipid droplets (LD) in liver. The perilipin family is a representative group of LD-associated proteins (Dalen et al., 2007; 
Itabe et al., 2017), and perilipin 5 (PLIN5) is important for accumulation and hydrolysis of TAG (Kimmel et al., 2010; Li et al., 2012). Perilipin 5 is highly expressed in oxidative tissues, including the heart, brown adipose tissue, skeletal muscle, and the liver (Dalen et al., 2007). Wang et al. (2015) reported that PLIN5 protein and mRNA abundance increased in steatotic liver from humans and obese $o b / o b$ mice, and knockout of PLIN5 alleviated steatosis in mice. Therefore, PLIN5 seems to play important roles in development of steatosis. Although PLIN5 was detected in the liver of healthy dairy cows during the periparturient period (Loor, 2010), whether this protein is associated with fatty liver after calving remains unknown.

Triacylglycerol accumulation in vivo and excessive lipid synthesis in vitro characterize bovine hepatic steatosis (Li et al., 2014). Alterations in the assembly and export of VLDL also contribute to the development of fatty liver (Bernabucci et al., 2004). Sevinc et al. (2003) reported that the serum content of VLDL decreased significantly in dairy cows with fatty liver. High levels of NEB-induced fatty acids are the pathological basis of fatty liver in cows (Bobe et al., 2004). Given that PLIN5 plays important roles in the development of fatty liver in humans and mice, we hypothesized that it may also mediate alterations in lipid synthesis and VLDL assembly caused by excessive fatty acid infiltration of the liver of dairy cows in early lactation.

\section{MATERIALS AND METHODS}

\section{Animals}

The study protocol was approved by the Ethics Committee for the Use and Care of Animals, Jilin University (Changchun, China). Dairy cows were selected from a 7,000-cow dairy farm located in Changchun City, Jilin Province, China. Cows were housed in a climate-controlled barn in individual tiestalls to reduce environmental effects. All cows received a rou- tine physical examination to ensure absence of other comorbidities. Cows had ad libitum access to the same diet (Supplemental Table S1; https://doi.org/10.3168/ jds.2018-15208). We chose lactating Holstein cows with similar number of lactations (median $=3$, range $=2$ to 4 ) and DIM (median $=8 \mathrm{~d}$, range $=6$ to $12 \mathrm{~d}$ ). The cows were classified as suspected fatty liver by veterinarians if feed intake, milk yield, or both were reduced and concentrations of blood ketones were elevated (Hippen et al., 1999; Jorritsma et al., 2001). Accordingly, we preselected 25 cows with suspected fatty liver and 22 healthy cows. Hepatic TAG content is the gold standard for diagnosing fatty liver in dairy cows (Bobe et al., 2004). Cows with hepatic TAG content $<1 \%$ (\% $\mathrm{g} / \mathrm{g}$ of wet weight) were classified as healthy, those with hepatic TAG content of 1 to $5 \%$ were classified as having mild fatty liver, those with hepatic TAG content of 5 to $10 \%$ were classified as having moderate fatty liver, and those with hepatic TAG content $>10 \%$ were classified as having severe fatty liver. Ten cows with fatty liver with a hepatic TAG content of 5 to $10 \%$ and 10 healthy cows with a hepatic TAG content of $<1 \%$ were selected. Body condition score was assigned based on a 1- to 5-point scale according to previous reports (Edmonson et al., 1989). Cows had access to a constant supply of fresh water and were milked twice daily at 0800 and $1530 \mathrm{~h}$. Blood samples were collected from the jugular vein between 0700 and $0800 \mathrm{~h}$ before feeding and centrifuged at $3,000 \times g$ for 15 min to obtain serum. The basic description of the cows is shown in Table 1.

After blood sample collection, liver biopsies were harvested by an experienced veterinarian using a percutaneous trocar approach that incorporates an O-ring near the base of the cannula (Hughes, 1962; Fry et al., 2018). Before liver biopsy, hair was clipped from the ninth intercostal space to the center of the paralumbar fossa, and the clipped area was washed with iodine soap. The biopsy site in the right 11th intercostal space was chosen after confirmation of correct placement with ul-

Table 1. Description of healthy cows (control; $\mathrm{n}=10)$ and cows with fatty liver $(\mathrm{n}=10)$

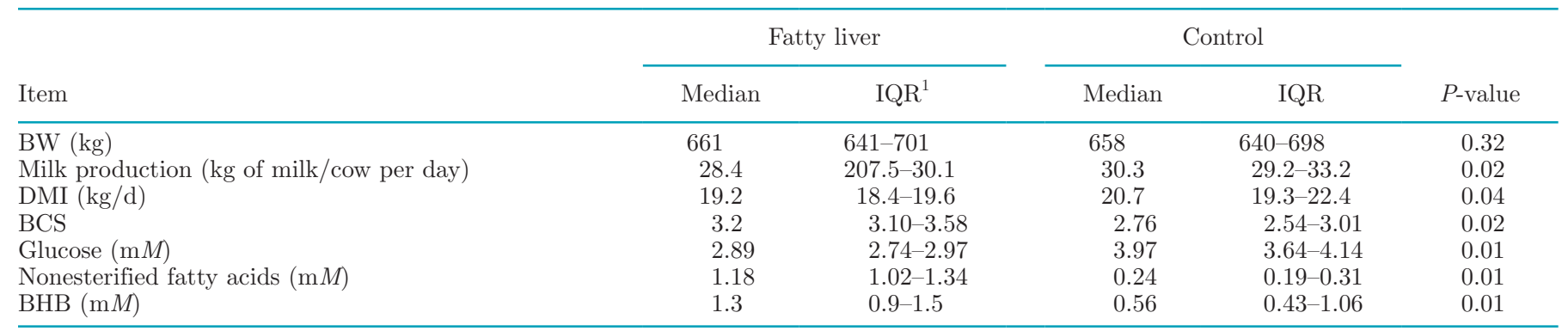

\footnotetext{
${ }^{1}$ Interquartile range.
} 
trasonography using a 7.5-MHz linear-array transducer (Ibex Pro, E.I. Medical Imaging, Loveland, CO) and $70 \%$ ethanol (Vet One, Boise, ID) as a coupling agent to visualize the area where the liver was found immediately adjacent to the peritoneum. Following surgical preparation of the site, the overlying skin and underlying intercostal muscle tissue were infiltrated with 10 $\mathrm{mL}$ of a $2 \%$ lidocaine solution (lidocaine $2 \% \mathrm{HCl}$; Vet One). An approximately $3-\mathrm{mm}$ skin incision at the 11th intercostal space was made using a \#22 scalpel blade to place the stainless steel trocar $(31 \mathrm{~cm}$ long and $7.5 \mathrm{~mm}$ in diameter) into the abdominal cavity, directing the point of the trocar toward the left elbow. Liver tissue biopsies ( $250 \mathrm{mg}$ from each cow) were immediately frozen in liquid nitrogen or fixed with $10 \%$ formaldehyde neutral buffer solution. The incision was closed with a disposable skin stapler (3M Precise, St. Paul, $\mathrm{MN}$ ) and coated with aluminum spray bandage.

\section{Determination of Blood Parameters}

Concentrations of glucose, BHB, and nonesterified fatty acids (NEFA) in serum were determined using a Hitachi 7170 autoanalyzer (Hitachi, Tokyo, Japan) with commercially available kits (BHB: cat. no. RB1008; NEFA: cat. no. FA115; glucose: cat. no. GL3815; Randox Laboratories, Crumlin, UK). The intra-assay and interassay coefficients of variation are reported in Supplemental Table S2 (https://doi.org/10.3168/jds .2018-15208).

\section{Histology}

Liver tissue was fixed in $10 \%$ formaldehyde neutral buffer solution before embedding in paraffin with a Tissue-Teko VIP 3000 processor. Embedded samples were sectioned to a thickness of $6 \mu \mathrm{m}$ and stained with hematoxylin and eosin. For immunohistochemistry analysis, the paraffin sections were stained with PLIN5 (sc-514296, Santa Cruz Biotechnology, Santa Cruz, CA). Last, the sections were viewed and photographed using an Olympus BX51 light microscope (Olympus, Tokyo, Japan) with an attached camera (Olympus E-330).

\section{Construction of Recombinant Adenoviruses and NEFA Preparation}

The empty adenovirus vector (Ad-GFP), PLIN5 overexpression adenovirus (Ad-PLIN5), and PLIN5 knockdown adenovirus (Ad-shPLIN5) were constructed by Hanbio (Shanghai, China). The PLIN5 short hairpin
RNA sequence was sense: 5'TGGCCACAGTGAATGATCTTGCCTG3', antisense: 5'CAGGCAAGATCATTCACTGTGGCCA'. The titer of virus reached $10^{10} \mathrm{pfu} / \mathrm{mL}$. A similar approach to our previous studies (Li et al., 2015) was used to evaluate the role of fatty acids in PLIN5 and steatosis. The NEFA was prepared according to a previous study (Du et al., 2018b) and diluted in $0.1 \mathrm{M} \mathrm{KOH}$ at $60^{\circ} \mathrm{C}$, and the $\mathrm{pH}$ of the solution was adjusted to 7.4 with hydrochloric acid $(1 M)$. The stock NEFA $(52.7 \mathrm{mM})$ solution included oleic acid $(22.9 \mathrm{mM})$, linoleic acid $(2.6 \mathrm{mM})$, palmitic acid (16.8 $\mathrm{m} M)$, stearic acid $(7.6 \mathrm{mM})$, and palmitoleic acid (2.8 $\mathrm{m} M)$.

\section{Cell Culture and Treatment}

Hepatocytes were isolated using the collagenase IV perfusion method as previously described (Du et al., 2018b). Briefly, liver tissue was collected from 6 Holstein calves (1 d old, female, 30-40 kg, healthy, fasting). The caudate lobe of the liver was obtained through surgical excision according to the methods in a previous study (Parker and Gaughan, 1988). Subsequently, the liver was perfused with perfusion solution A $(140 \mathrm{mM}$ $\mathrm{NaCl}, 10 \mathrm{~m} M$ HEPES, $6.7 \mathrm{~m} M \mathrm{KCl}, 0.5 \mathrm{~m} M$ EDTA, and $2.5 \mathrm{mM}$ glucose; $\mathrm{pH} 7.2-7.4 ; 37^{\circ} \mathrm{C}$ ) at a flow rate of $50 \mathrm{~mL} / \mathrm{min}$ for $12 \mathrm{~min}$. Then, the liver was perfused with solution B (140 $\mathrm{m} M \mathrm{NaCl}, 30 \mathrm{~m} M$ HEPES, $6.7 \mathrm{~m} M \mathrm{KCl}, 5 \mathrm{~m} M \mathrm{CaCl}_{2}$, and $2.5 \mathrm{~m} M$ glucose; $\mathrm{pH}$ $7.2-7.4 ; 37^{\circ} \mathrm{C}$ ) at a flow rate of $50 \mathrm{~mL} / \mathrm{min}$ for $3 \mathrm{~min}$ until the liquid became clear. Subsequently, the liver was perfused with a collagenase IV solution $(0.1 \mathrm{~g}$ of collagenase IV dissolved in $0.5 \mathrm{~L}$ of perfusion solution $\mathrm{B}, \mathrm{pH} 7.2-7.4,37^{\circ} \mathrm{C}$ ) at a flow rate of $20 \mathrm{~mL} / \mathrm{min}$ for 15 to $20 \mathrm{~min}$. The liver was moved to a sterile flat plate after digestion, and $100 \mathrm{~mL}$ of fetal bovine serum (Hyclone Laboratories, Logan, UT) was added to terminate the collagenase digestion. The liver was cut open, and the liver capsule, blood vessels, fat, and connective tissue were removed. Any parts of the caudate lobe that were incompletely digested were cut away, and the remainder of the liver parenchyma was cut into pieces and filtered sequentially with 100 -mesh $(150 \mu \mathrm{m})$ and 200-mesh $(75 \mu \mathrm{m})$ cell sieves. The hepatocyte suspension was washed twice with basic medium $\left(4^{\circ} \mathrm{C}\right)$ and centrifuged for 10 min at $500 \times g$ before resuspension in adherent medium. Isolated hepatocytes were seeded into a 6 -well tissue culture plate at $1 \times 10^{6}$ cells $/ \mathrm{mL}$ and incubated at $37^{\circ} \mathrm{C}$ under $5 \% \mathrm{CO}_{2}$. The medium was replaced with growth medium containing $10 \%$ fetal bovine serum every $24 \mathrm{~h}$. After $3 \mathrm{~d}$ of culture, the cells were serum-starved overnight, treated with NEFA, or transfected with adenovirus. 


\section{TAG Content Determination}

Liver tissue $(\sim 20 \mathrm{mg})$ was homogenized in ice-cold PBS (1:20, wt/vol) using an ultra-Turrax T25 homogenizer (Rose Scientific Ltd., Edmonton, AB, Canada). Hepatocytes were washed with ice-cold PBS twice. Liver and hepatocyte TAG concentration was detected using commercial ELISA kits (E1013; Applygen Technologies Inc., Beijing, China) according to the manufacturer's protocol. Total protein concentration was estimated by the bicinchoninic acid method (P1511; Applygen Technologies Inc.). The intra-assay and interassay coefficients of variation are reported in Supplemental Table S2 (https://doi.org/10.3168/jds.2018-15208).

\section{Very Low Density Lipoprotein Apolipoprotein B Content Determination}

Very low density lipoprotein apolipoprotein B (VLDL-ApoB) in serum and culture supernatant was determined as previously described (Zulewski et al., 1998). In brief, the VLDL in serum and culture supernatant were isolated by sequential ultracentrifugation at $1.006 \mathrm{~g} / \mathrm{mL}$ using a Type Ti 70.1 rotor (Beckman Coulter, Nyon, Switzerland). Sodium azide was added to a final concentration of $0.1 \mathrm{mg} / \mathrm{mL}$ as an antimicrobial agent, and EDTA was added to a final concentration of $0.5 \mathrm{~m} M$. Samples were kept at $4^{\circ} \mathrm{C}$ during preparation of the fractions and stored at $-70^{\circ} \mathrm{C}$. The VLDL-ApoB concentrations in serum and culture supernatant were assayed by nephelometry using a Behring apparatus and ApoB antibody (ab7616, Abcam, Cambridge, UK). Concentration of VLDL-ApoB was determined in duplicate for each sample. The intra-assay and interassay coefficients of variation are reported in Supplemental Table S2 (https://doi.org/10.3168/jds.2018-15208).

\section{Oil Red O Staining}

The cells were fixed in $10 \%$ formalin for $15 \mathrm{~min}$. Next, the cells were washed with ice-cold PBS twice and subsequently with $60 \%$ (vol/vol) isopropanol for 2 min, stained with $0.5 \%$ (wt/vol) Oil Red O solution for 15 min, washed with $60 \%$ isopropanol and subsequently with ice-cold PBS, and then counterstained with hematoxylin before microscopy.

\section{Quantitative Reverse-Transcription PCR Assay}

The RNA was isolated from liver or hepatocytes using Trizol (Takara Biotechnology Co. Ltd., Dalian, China) according to the manufacturer's instructions. The RNA concentration and quality were measured using a K5500 microspectrophotometer (Beijing Kaiao Technology Development Ltd., Beijing, China) and electrophoresis (1\% agarose gels). Then, $1 \mu \mathrm{g}$ of total RNA in each sample was reverse transcribed to cDNA (TaKaRa Biotechnology Co. Ltd., Tokyo, Japan) according to the supplier's protocol. The mRNA abundance was detected with the 7500 Real-Time PCR System (Applied Biosystems, Foster City, CA) using an SYBR green plus reagent kit (Roche, Norwalk, CT). The conditions were as follows: initial denaturation at $94^{\circ} \mathrm{C}$ for $2 \mathrm{~min}, 35$ cycles of amplification (denaturation at $94^{\circ} \mathrm{C}$ for $10 \mathrm{~s}$, annealing at $60^{\circ} \mathrm{C}$ for $15 \mathrm{~s}$, and extension at $72^{\circ} \mathrm{C}$ for $30 \mathrm{~s}$ ), and extension at $72^{\circ} \mathrm{C}$ for $5 \mathrm{~min}$. The cycles-to-threshold values of GAPDH, ubiquitin, and $\beta$-actin were not affected by liver fat content and different treatments, thus indicating the usefulness as internal control genes (Farke et al., 2008; Du et al., 2017; Supplemental Figure S1; https://doi.org/ 10.3168/jds.2018-15208). Thus, the relative expression of each target gene was normalized to GAPDH, ubiquitin, and $\beta$-actin. Abundance of target genes was calculated with the $2^{-\Delta \Delta \mathrm{CT}}$ method. Primer sets are reported in Supplemental Table S3 (https://doi.org/10 $.3168 /$ jds.2018-15208). For in vivo quantitative reversetranscription PCR experiments, the PCR reaction was performed in triplicate for each cow and 10 cows per group were included. For in vitro quantitative reversetranscription PCR experiments, the PCR reaction was performed 9 times for each group.

\section{Protein Extraction and Western Blotting}

Western blotting assays were performed as described previously (Sun et al., 2017). Protein was isolated from liver or hepatocytes using a commercial protein extraction kit (Sangon Biotech Co. Ltd., Shanghai, China) according to the manufacturer's instructions. The concentration of protein was determined using the bicinchoninic acid Protein Assay Kit (P1511; Applygen Technologies Inc.). A total of $30 \mu \mathrm{g}$ of protein from each sample was separated on 8 to $15 \%$ Tris-glycine gels with known molecular weight markers (Sangon Biotech Co. Ltd.). Subsequently, the proteins were electroblotted onto $0.45-\mu \mathrm{m}$ PVDF membranes. The membranes were blocked with $5 \%$ nonfat milk; then, blocked membranes were hybridized overnight at $4^{\circ} \mathrm{C}$ with antibodies against $\beta$-actin (internal control; 1:2,000, ab8226, Abcam), PLIN5 (1:1,000, sc-514296, Santa Cruz Biotechnology), sterol regulatory element-binding protein 1 (SREBP-1; 1:500, NB100-2215, Novus Biologicals, Littleton, CO), fatty acid synthase (FAS; 1:500, no. 3180, Cell Signaling Technology Inc., Danvers, MA), acetyl-coA carboxylase 1 (ACC1; 1:500, ab45174, 
Abcam), diacylglycerol acyltransferase 1 (DGAT1; 1:500, ab54037, Abcam), diacylglycerol acyltransferase 2 (DGAT2; 1:500, ab59493, Abcam), microsomal triglyceride transfer protein (MTP; 1:500, sc-135994, Santa Cruz Biotechnology), apolipoprotein E (ApoE; 1:500, sc-13521, Santa Cruz Biotechnology), and apolipoprotein B100 (ApoB100; 1:1,000; ab7616, Abcam), followed by incubation with horseradish peroxidaseconjugated anti-mouse, anti-goat, or anti-rabbit antibody (Boster, Wuhan, China). Immunoreactive bands were detected using an enhanced chemiluminescence solution (Pierce Biotechnology Inc., Chicago, IL). Last, the bands were imaged using a protein imager (ProteinSimple, Santa Clara, CA).

\section{Statistical Analysis}

The results are expressed as the mean \pm standard error of the mean. Data from 3 independent experiments were subjected to statistical analysis using GraphPad Prism 5 (GraphPad InStat Software, San Diego, CA). In the in vivo studies, data from quantitative reversetranscription PCR and Western blotting were normally distributed and analyzed with paired $t$-test; other data were non-normally distributed and analyzed with Wilcoxon signed rank test. In the in vitro studies, comparisons among groups were analyzed using the 1-way ANOVA with subsequent Bonferroni correction. A Pvalue $<0.05$ was considered statistically significant, and a $P$-value $<0.01$ was considered highly significant.

\section{RESULTS}

\section{Increased TAG Synthesis and Decreased VLDL Assembly in Steatotic Liver}

Hepatic TAG content (\% wet weight) in dairy cows with fatty liver (mean $=8.03 \% \mathrm{~g} / \mathrm{g}$ of wet weight) was significantly greater $(P<0.01)$ than that in healthy cows $($ mean $=0.42 \% \mathrm{~g} / \mathrm{g}$ of wet weight; Figure $1 \mathrm{~A}$ ). Furthermore, hematoxylin and eosin staining revealed a clear state of steatosis, including severe panlobular micro- and macrovesicular steatosis (Figure 1B). The protein abundance of SREBP-1, FAS, ACC1, DGAT1, and DGAT2 was greater $(P<0.01)$ in liver of dairy cows with fatty liver compared with healthy cows (Figure $1 \mathrm{C}$ and D). Similarly, mRNA abundance of SREBP1, $F A S, A C C 1, D G A T 1$, and DGAT2 was greater $(P<$ 0.05 and $P<0.01)$ in liver of dairy cows with fatty liver compared with healthy cows (Figure 1E). Furthermore, serum VLDL-ApoB content was significantly lower $(P$ $<0.01)$ in dairy cows with fatty liver compared with healthy cows (Figure 1F). The protein abundance of MTP, ApoB100, and ApoE-key apoliproteins involved in the assembly of VLDL - was markedly lower $(P<$ 0.05 and $P<0.01$ ) in liver of dairy cows with fatty liver compared with healthy cows (Figure $1 \mathrm{G}$ and $\mathrm{H}$ ). In addition, mRNA abundance of MTP, ApoB100, and ApoE was markedly lower $(P<0.01)$ in liver of dairy cows with fatty liver compared with healthy cows (Figure 1I).

\section{Increased PLIN5 Expression in Steatotic Liver}

Immunohistochemistry results indicated that PLIN5 was highly expressed in steatotic liver and localized to LD (Figure 2A). Western blot results showed that the protein abundance of PLIN5 was greater $(P<0.01)$ in liver of dairy cows with fatty liver compared with healthy cows (Figure $2 \mathrm{~B}$ and $\mathrm{C}$ ). A similar trend in mRNA abundance of PLIN5 was also observed $(P<$ 0.01 , Figure 2D), indicating overproduction of the protein with fatty liver.

\section{PLIN5 Overexpression in Bovine Hepatocytes Promoted Lipid Accumulation}

The overexpression of PLIN5 promoted TAG accumulation in bovine hepatocytes $(P<0.01$, Figure $3 \mathrm{~A})$. Oil Red O staining showed a similar result, with the amount and size of LD being significantly greater in the Ad-PLIN5 group (Figure 3B). The protein abundance of SREBP-1, FAS, ACC1, DGAT1, and DGAT2 was significantly greater $(P<0.01)$ in the Ad-PLIN5 group compared with the Ad-GFP group (Figure 3C and D). Similarly, the mRNA abundance of SREBP1, FAS, ACC1, DGAT1, and DGAT2 was also significantly greater $(P<0.01)$ in the Ad-PLIN5 group compared with the Ad-GFP group (Figure 3E). Furthermore, PLIN5 overexpression significantly decreased the VLDL-ApoB content in the supernatant $(P<0.01$, Figure $3 \mathrm{~F}$ ). Consistent with the VLDL-ApoB content, PLIN5 overexpression significantly decreased the protein abundance of MTP, ApoB100, and ApoE $(P<$ 0.05 and $P<0.01$; Figure $3 \mathrm{G}$ and $\mathrm{H}$ ). In addition, the mRNA abundance of MTP, ApoB100, and ApoE had a similar trend $(P<0.05$ and $P<0.01$, Figure $3 \mathrm{I})$.

\section{NEFA Promoted Lipid Synthesis and Inhibited VLDL Assembly in Hepatocytes}

Treatment with $0.6(P<0.05), 1.2$, and $2.4 \mathrm{mM}$ $(P<0.01)$ NEFA significantly increased the protein abundance of PLIN5 (Figure 4A and B). Furthermore, treatment with $0.6(P<0.05), 1.2$, and $2.4 \mathrm{~m} M(P<$ $0.01)$ NEFA significantly increased the protein abundance of SREBP-1, FAS, ACC1, DGAT1, and DGAT2 
A

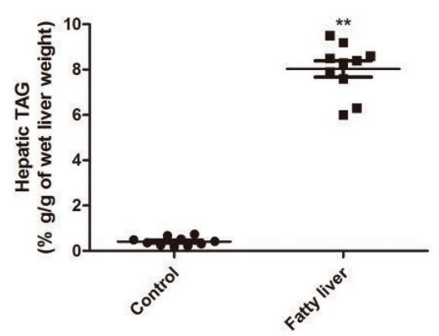

B

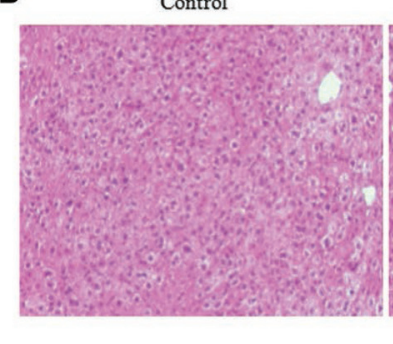

Fatty liver

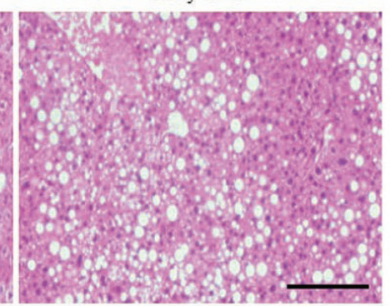

C

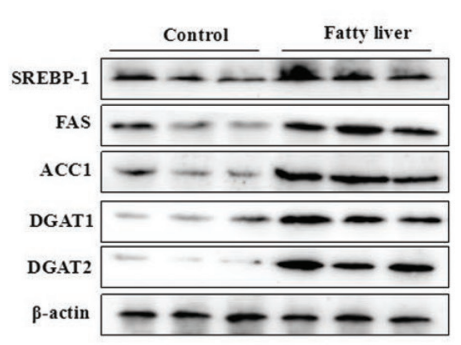

D

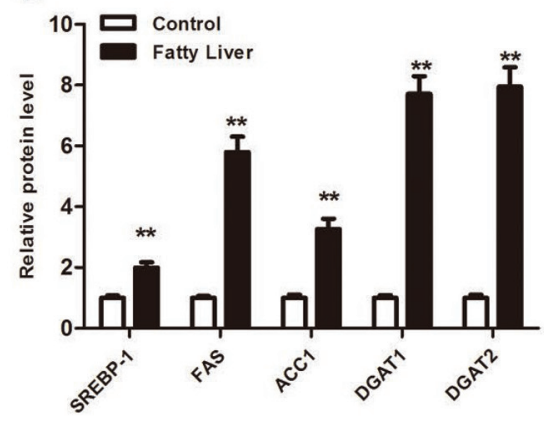

E D control

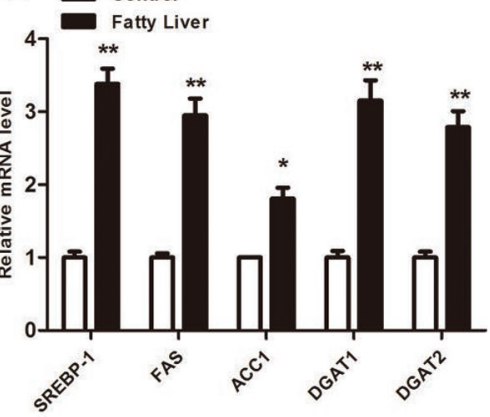

F

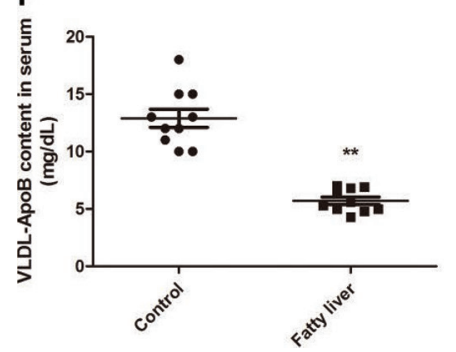

G

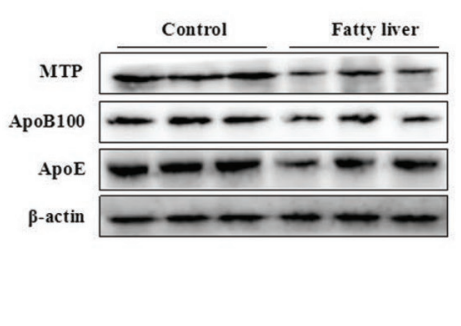

H

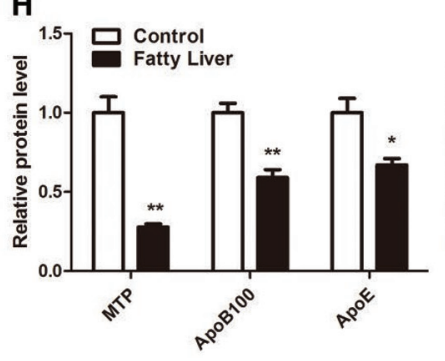

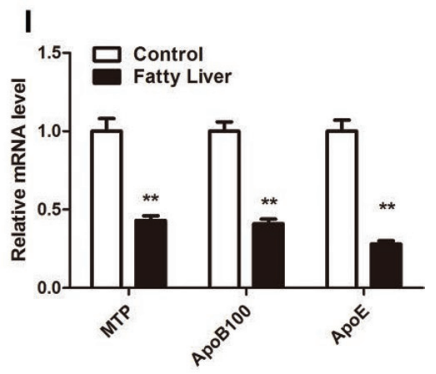

Figure 1. Dairy cows with fatty liver exhibited hepatic fat accumulation, increased de novo fatty acids synthesis, and decreased VLDL assembly. (A) Hepatic triacylglycerol (TAG) content. (B) Hematoxylin and eosin staining of liver sections; scale bar = $100 \mu \mathrm{m}$. (C) Western blot analysis of sterol regulatory element-binding protein 1 (SREBP-1), fatty acid synthase (FAS), acetyl-coA carboxylase 1 (ACC1), diacylglycerol acyltransferase 1 (DGAT1), and diacylglycerol acyltransferase 2 (DGAT2). (D) Relative protein expression levels of SREBP-1, FAS, ACC1, DGAT1, and DGAT2. (E) Relative mRNA expression levels of SREBP-1, FAS, ACC1, DGAT1, and DGAT2. (F) Serum very low density lipoprotein apolipoprotein B (VLDL-ApoB) content. (G) Western blot analysis of microsomal triglyceride transfer protein (MTP), apolipoprotein B100 (ApoB100), and apolipoprotein E (ApoE). (H) Relative protein expression levels of MTP, ApoB100, and ApoE. (I) Relative mRNA expression levels of MTP, ApoB100, and ApoE. Figure 1A and F were analyzed with Wilcoxon signed rank test and expressed as the mean \pm SEM $(\mathrm{n}=10$ /group). Figure $1 \mathrm{C}, \mathrm{D}, \mathrm{E}, \mathrm{G}, \mathrm{H}$, and I were analyzed with paired $t$-tests and expressed as the mean $\pm \mathrm{SEM}(\mathrm{n}=10 /$ group). $* P<0.05$, ${ }^{* *} P<0.01$ compared with the control group.

(Figure 4A and B), but 1.2 and $2.4 \mathrm{mM}(P<0.05)$ NEFA decreased the abundance of MTP, ApoB100, and ApoE (Figure 4C and D). The TAG content in hepatocytes was greater, whereas VLDL-ApoB content in the supernatant was lower in the cultures receiving $0.6(P<0.05), 1.2$, and $2.4 \mathrm{mM}(P<0.01)$ NEFA (Figure $4 \mathrm{E}$ and $\mathrm{F}$ ).

\section{PLIN5 Knockdown in Hepatocytes Attenuated the TAG Accumulation Caused by NEFA}

Knockdown of PLIN5 markedly attenuated the upregulation of the protein and mRNA abundance of PLIN5 induced by NEFA $(P<0.01$, Figure 5A, B, and C). Subsequently, knockdown of PLIN5 attenuated the upregulation of protein and mRNA for SREBP-1, FAS, ACC1, DGAT1, and DGAT2 induced by NEFA $(P<0.01$, Figure $5 \mathrm{~A}, \mathrm{~B}$, and $\mathrm{C})$. It also attenuated the NEFA-induced TAG content $(P<0.01$, Figure $5 \mathrm{D})$. Oil Red O staining revealed a similar result, with the amount of LD being lower in the PLIN5 knockdown adenovirus (Ad-shPLIN5) $+1.2 \mathrm{~m} M$ NEFA cultures (Figure 5E). Furthermore, PLIN5 knockdown normalized the protein and mRNA abundance of MTP, ApoB100, and ApoE $(P<0.05$ and $P<0.01$, Figure $5 \mathrm{~F}, \mathrm{G}$, and $\mathrm{H})$ and further alleviated the inhibitory effect of NEFA on VLDL-ApoB content in supernatant $(P<0.01$, Figure 5I $)$. 


\section{DISCUSSION}

High levels of NEB-induced fatty acid release at the beginning of lactation are the pathological basis of fatty liver in cows ( $\mathrm{Li}$ et al., 2014). Excessive amounts of fatty acids entering the liver are re-esterified and stored as TAG in hepatocytes, which results in fatty liver. Our previous study found that lipid synthesis and number of mitochondria increased in the liver of dairy cows with mild fatty liver, which we speculated were adaptive mechanisms of the liver in response to NEB (Du et al., 2018a). In the present study, we preselected 25 cows with suspected fatty liver and found that 16 cows had fatty liver, 13 of which were moderate fatty liver (hepatic TAG content $5-10 \%$ ) and 3 of which were mild fatty liver (hepatic TAG content 1-5\%). Thus, cows with moderate fatty liver were selected in this study. Notably, in this study, the hepatic TAG content of dairy cows with fatty liver was $8.03 \%(\mathrm{~g} / \mathrm{g}$ of wet weight) compared with $3.01 \%(\mathrm{~g} / \mathrm{g}$ of wet weight) in the study of Du et al. (2018a). Thus, clearly, the present study resulted in a more pronounced degree of TAG accumulation in the liver.

The LD membrane-associated PLIN5 plays important roles in the development of hepatic steatosis of humans and mice (Wang et al., 2015). The greater
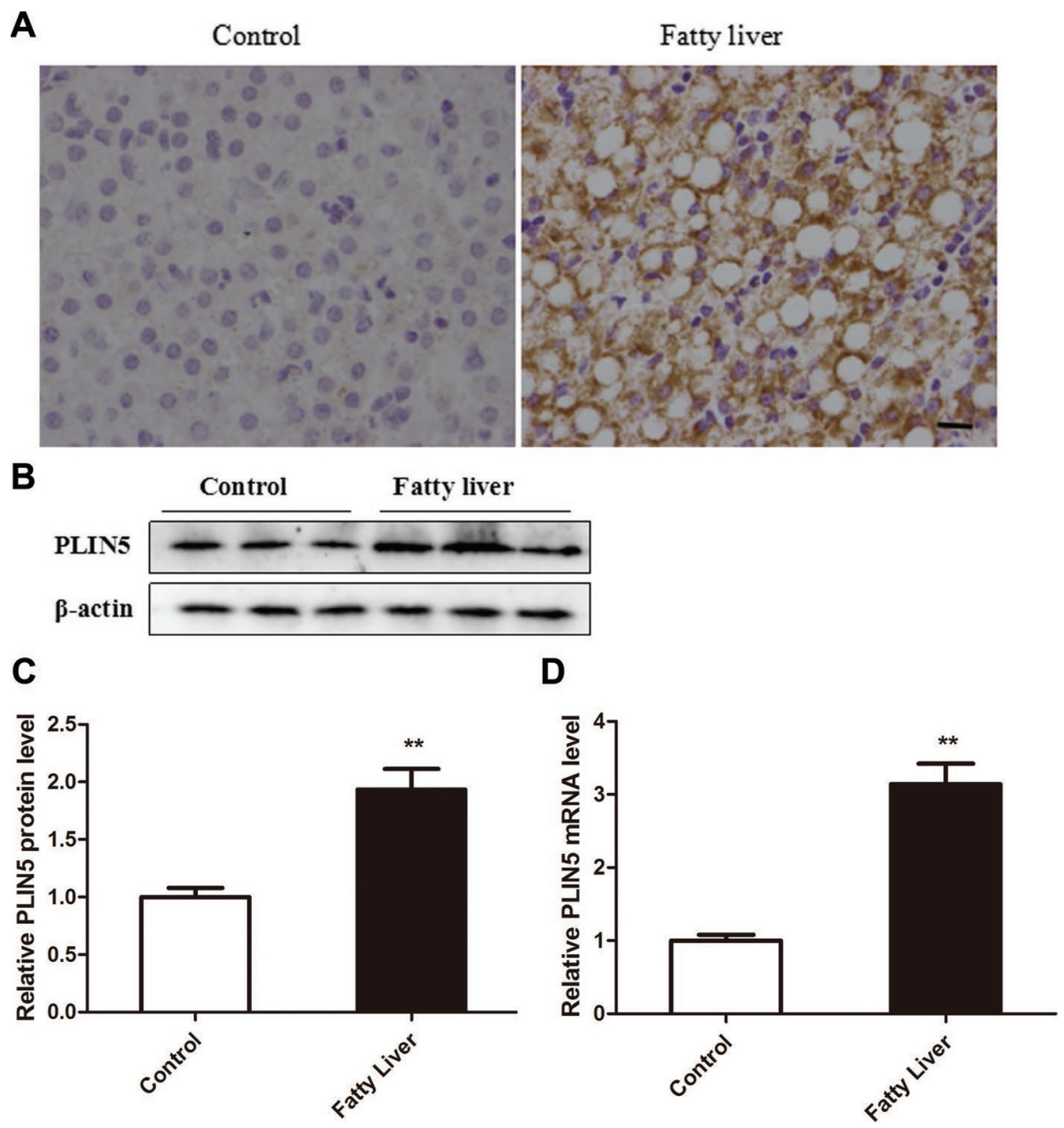

Figure 2. Increased perilipin 5 (PLIN5) expression in steatotic livers of dairy cows. (A) Immunohistochemistry staining of liver sections with PLIN5 antibody in dairy cows with hepatic steatosis; scale bar $=50 \mu \mathrm{m}$. (B) Western blot analysis of PLIN5. (C) Relative protein expression level of PLIN5. (D) Relative mRNA expression levels of PLIN5. Data were analyzed with paired $t$-tests and expressed as the mean \pm SEM (n $=10 /$ group). ${ }^{* *} P<0.01$ compared with the control group. 
A

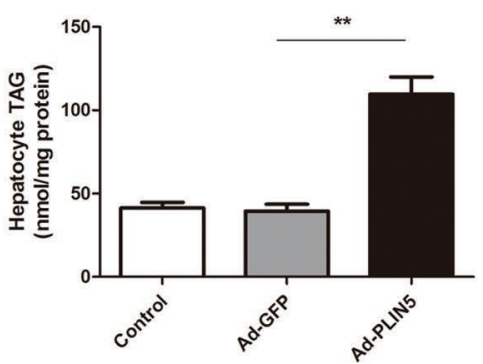

C

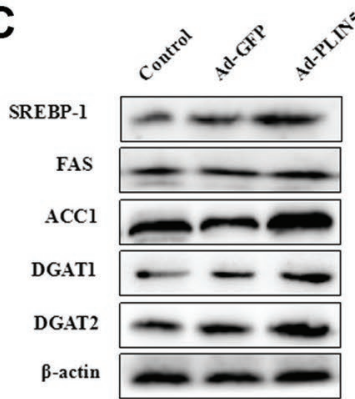

$\mathbf{F}$

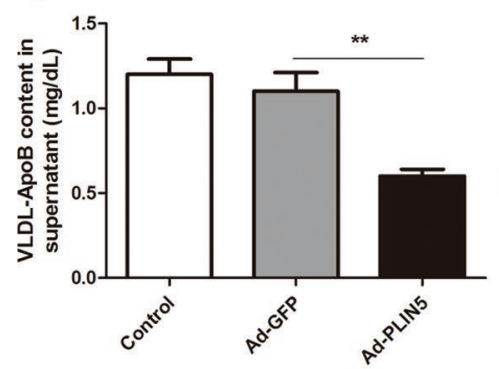

B
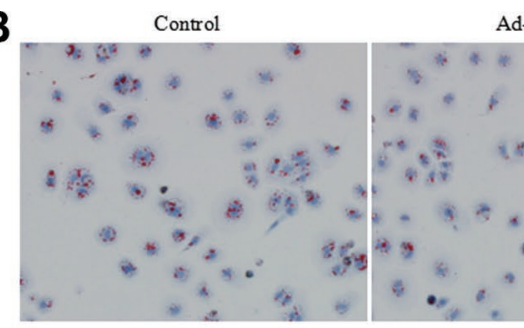

Ad-GFP

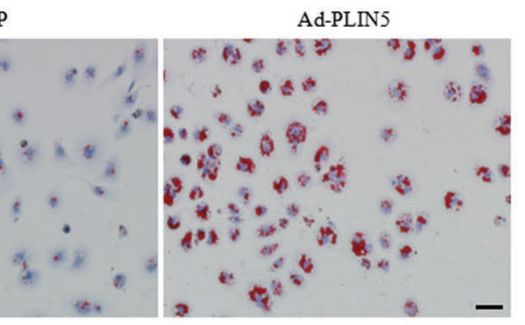

D

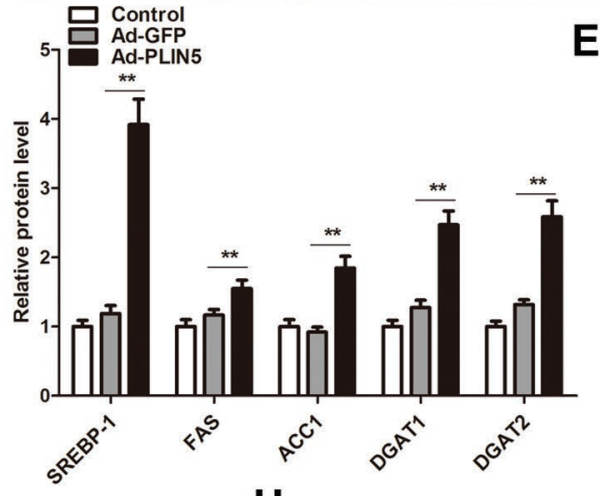

E ${ }_{5}$ 号 Control

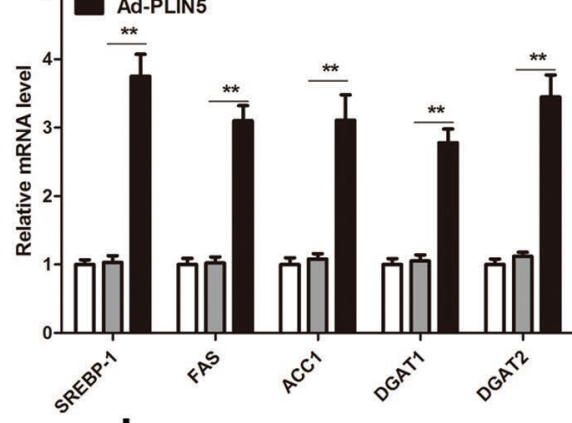

G

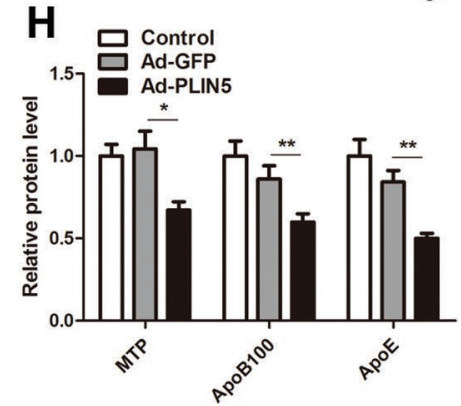

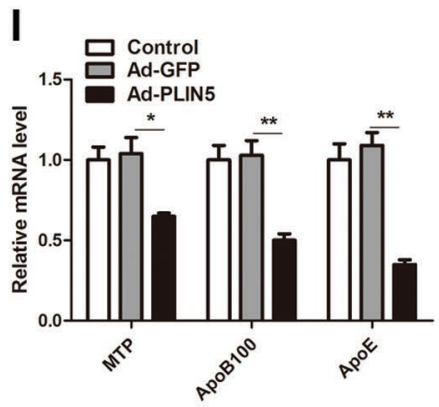

Figure 3. Perilipin 5 (PLIN5) overexpression in bovine primary hepatocytes promoted hepatic lipid synthesis and inhibited the very low density lipoprotein (VLDL) assembly. The cells were infected with adenovirus for $48 \mathrm{~h}$ that overexpress PLIN5 (Ad-PLIN5 group), the control group was cultured in Dulbecco's modified Eagle medium/F12 without adenovirus or empty adenovirus vector, and the Ad-GFP group was infected with empty adenovirus vector for $48 \mathrm{~h}$. (A) Triacylglycerol (TAG) content in hepatocytes. (B) Representative Oil Red O staining in hepatocytes; scale bar $=100 \mu \mathrm{m}$. (C) Western blot analysis of sterol regulatory element-binding protein 1 (SREBP-1), fatty acid synthase (FAS), acetyl-coA carboxylase 1 (ACC1), diacylglycerol acyltransferase 1 (DGAT1), and diacylglycerol acyltransferase 2 (DGAT2). (D) Relative protein expression levels of SREBP-1, FAS, ACC1, DGAT1, and DGAT2. (E) Relative mRNA expression levels of SREBP-1, FAS, ACC1, DGAT1, and DGAT2. (F) Very low density lipoprotein apolipoprotein B (VLDL-ApoB) content in supernatant. (G) Western blot analysis of microsomal triglyceride transfer protein (MTP), apolipoprotein B100 (ApoB100), and apolipoprotein E (ApoE). (H) Relative protein expression levels of MTP, ApoB100, and ApoE. (I) Relative mRNA expression levels of MTP, ApoB100, and ApoE. Comparisons among groups were calculated using a 1-way ANOVA with subsequent Bonferroni correction. The data presented are the mean \pm SEM. ${ }^{*} P<0.05,{ }^{* *} P<0.01$ compared with the Ad-GFP group.

hepatic abundance of PLIN5 in cows with fatty liver in this study suggests its involvement in the induction of hepatic steatosis. The in vitro data revealed that NEFA work through PLIN5 to increase TAG accumulation in hepatocytes. Those responses were further accompanied by increased lipid synthesis and inhibition of VLDL assembly. Hence, data from the present study extend the study of processes related to fatty liver development in dairy cows by Du et al. (2018a).

In nonruminants, hepatic lipogenesis is well known to contribute to the progression of hepatic steatosis, with SREBP-1 acting as a transcription factor regulating de novo lipogenesis through its control of ACC1 and FAS transcription (Ferré and Foufelle, 2010). Acetyl-coA carboxylase 1 is a rate-limiting enzyme in fatty acid synthesis and converts acetyl-CoA to malonyl-CoA. Subsequently, FAS catalyzes the production of palmitic acid primarily (Wakil, 1989) that can furnish substrate for TAG synthesis via the enzymes DGAT1 or DGAT2 (Wilfling et al., 2013). Although classical work with sheep and cattle demonstrated that the ruminant liver is not quantitatively important in terms of lipogenesis (Ballard et al., 1972; Ingle et al., 1972), abundance of SREBP1 (and citrate synthase) during the peripar- 
turient period in liver is responsive to dietary energy density (Khan et al., 2014). A previous study revealed that dairy cows with fatty liver also experience alterations in lipid metabolism-related enzymes ( $\mathrm{Li}$ et al., 2015). Thus, it is possible that during conditions when lipogenic precursors are increased within the liver, the lipogenic program is enhanced. Furthermore, exogenous NEFA (i.e., resulting from adipose lipolysis) would provide substrate for esterification into TAG. Such adaptations along with the greater blood NEFA concentrations explain the upregulation of SREBP-1, FAS, ACC1, DGAT1, and DGAT2 in cows with fatty liver. These results indicate that both the elevation of fatty acid and TAG synthesis may be partly responsible for hepatic fat accumulation in dairy cows.

Excessive fat accumulation in liver can inhibit VLDL assembly (Bobe et al., 2004), hence preventing the normal export of TAG out of the liver (Kleppe et al.,
1988). The synthesis and secretion of VLDL in liver are complex processes controlled by the action of ApoB100, ApoE, and MTP (Katoh, 2002). The proteins ApoB100 and ApoE are the most important structural components of VLDL; ApoB100 is the TG-binding protein in VLDL and is necessary for stabilizing the VLDL particles (Bernabucci et al., 2004). The MTP appears to be involved in the first step of lipidation of the newly synthesized ApoB100 molecule, resulting in the formation of nascent lipoprotein particles (Wetterau et al., 1997). Marcos et al. (1990) reported that the level of hepatic ApoB mRNA in cows with fatty liver was lower compared with healthy cows and concluded that hepatic apolipoprotein synthesis is impeded during fatty liver. In addition, Uchida et al. (1992) demonstrated that the plasma concentration of ApoB100 in dairy cows with fatty liver was lower compared with healthy cows. In this study, the lower abundance of hepatic
A

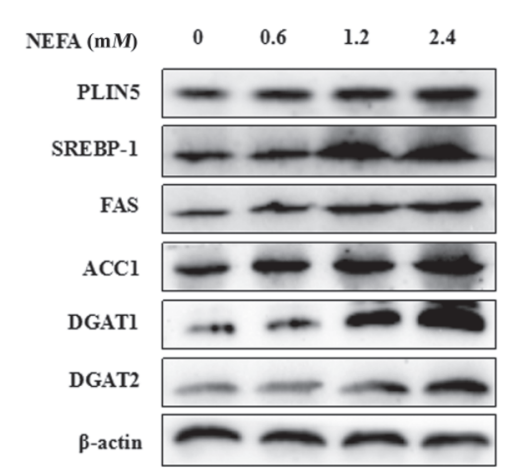

C

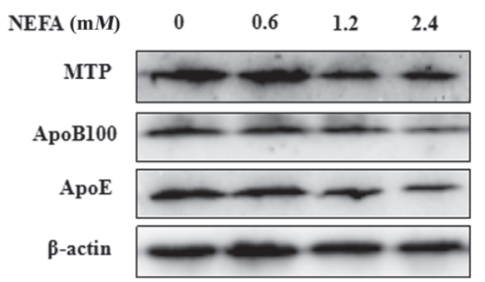

B

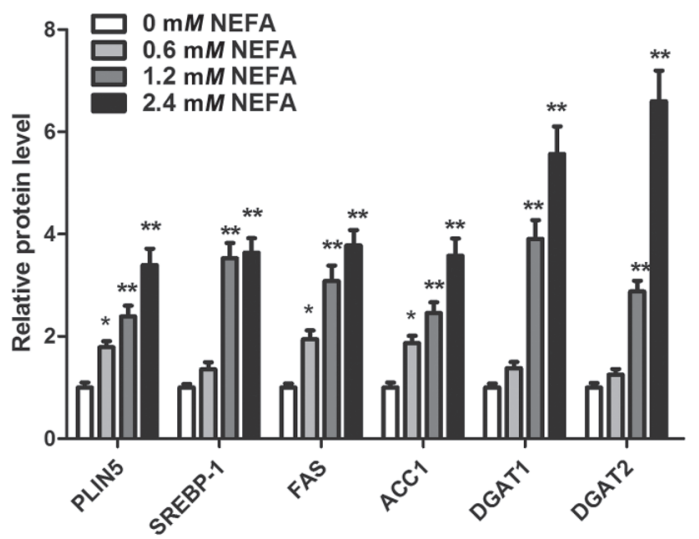

D

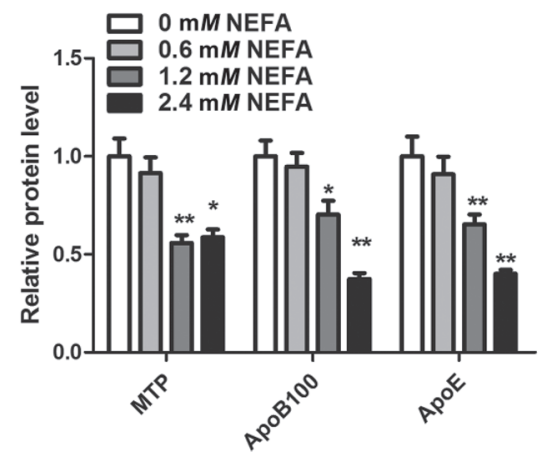

E

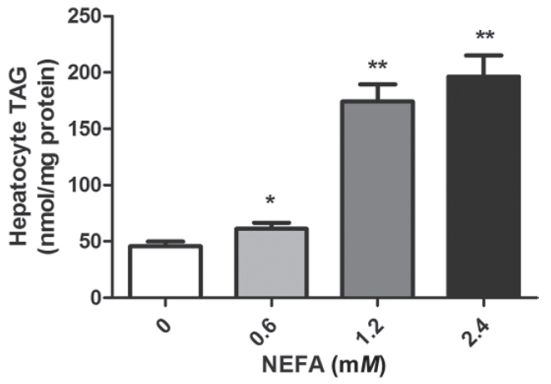

$\mathbf{F}$

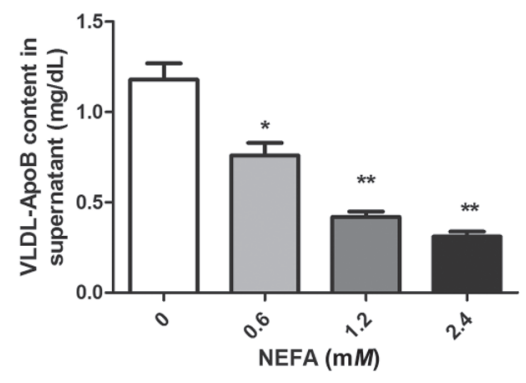

Figure 4. Nonesterified fatty acids (NEFA) promoted the lipid synthesis and inhibited the very low density lipoprotein (VLDL) assembly in hepatocytes. Cells were treated with $0,0.6,1.2$, or $2.4 \mathrm{~m} M$ NEFA and $2 \%$ fatty acid-free BSA for $24 \mathrm{~h}$. (A) Western blot analysis of perilipin 5 (PLIN5), sterol regulatory element-binding protein 1 (SREBP-1), fatty acid synthase (FAS), acetyl-coA carboxylase 1 (ACC1), diacylglycerol acyltransferase 1 (DGAT1), and diacylglycerol acyltransferase 2 (DGAT2). (B) Relative protein expression levels of PLIN5, SREBP-1, FAS, ACC1, DGAT1, and DGAT2. (C) Western blot analysis of microsomal triglyceride transfer protein (MTP), apolipoprotein B100 (ApoB100), and apolipoprotein E (ApoE). (D) Relative protein expression levels of MTP, ApoB100, and ApoE. (E) Triacylglycerol (TAG) content in hepatocytes. (F) Very low density lipoprotein apolipoprotein B (VLDL-ApoB) content in supernatant. Comparisons among groups were calculated using a 1-way ANOVA with subsequent Bonferroni correction. The data presented are the mean \pm SEM. ${ }^{*} P<0.05,{ }^{* *} P<0.01$ compared with the $0 \mathrm{~m} M$ NEFA group. 
MTP, ApoB100, and ApoE along with lower blood VLDL-ApoB concentration in cows with fatty liver suggested that impaired assembly of VLDL contributes to TAG accumulation in hepatocytes. Furthermore, the impaired assembly of VLDL at the molecular level may partly explain the inherently low rate of hepatic VLDL secretion in cows and the high incidence of fatty liver in dairy cows. Taken together, the available data con-
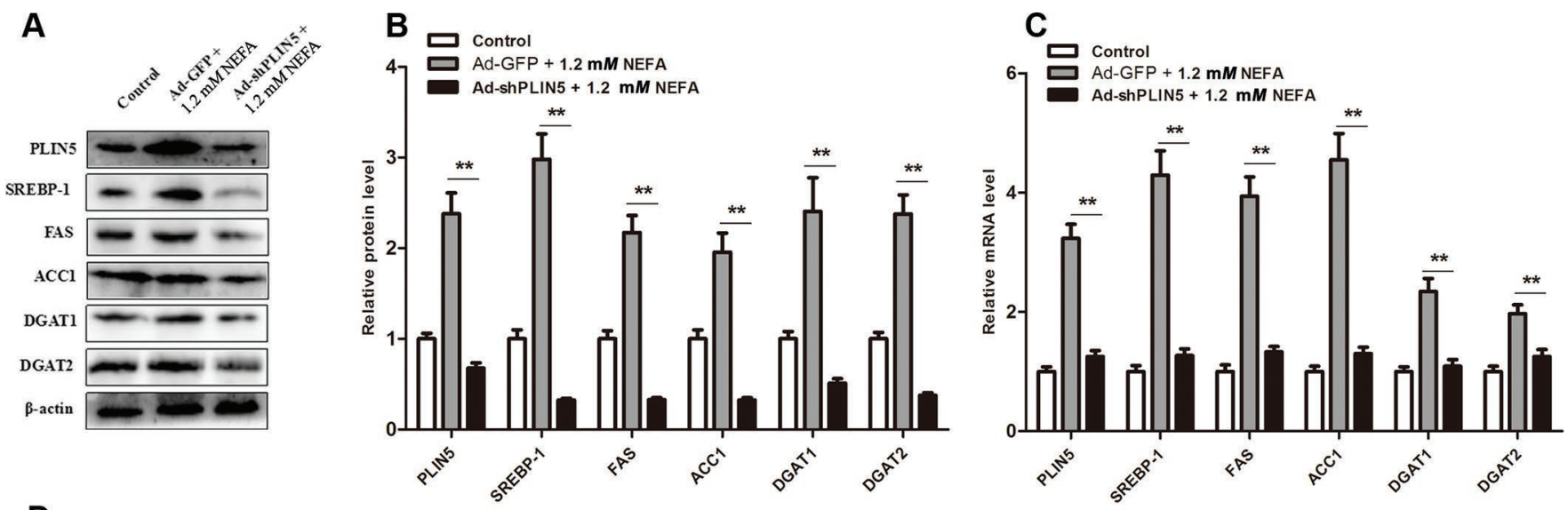

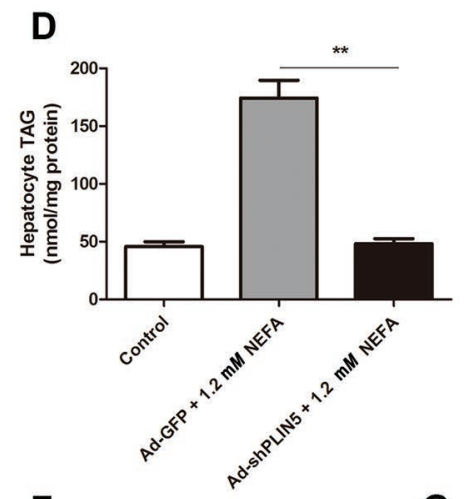

$\mathbf{F}$

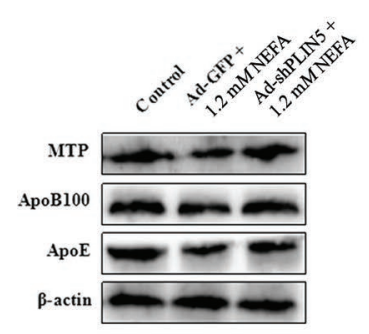

E
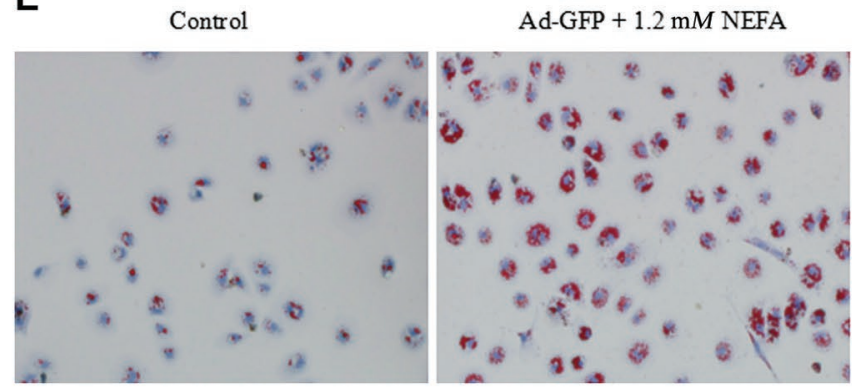

H

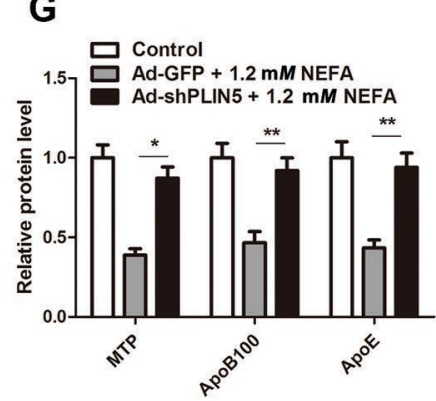

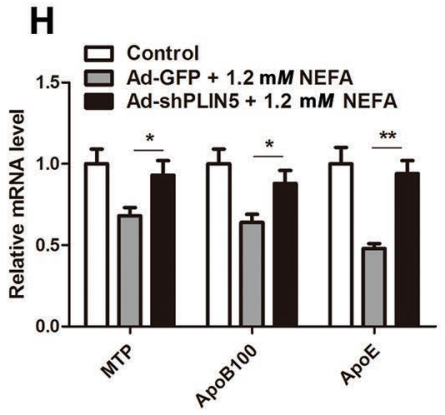
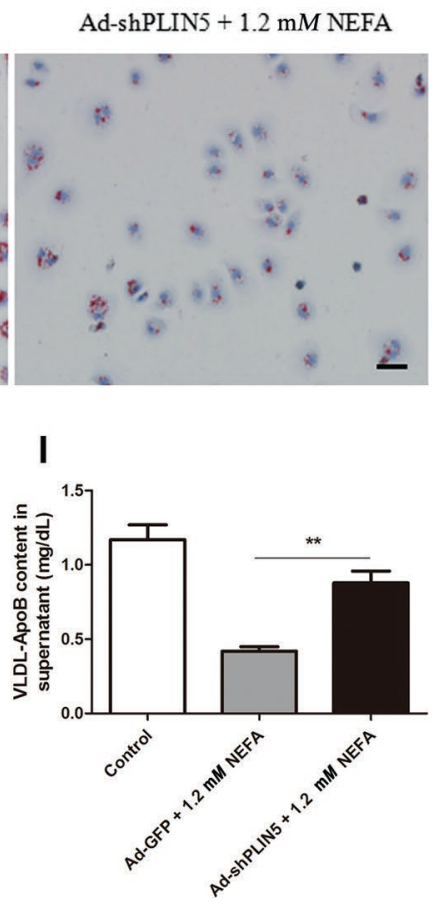

Figure 5. Perilipin 5 (PLIN5) deficiency in hepatocytes attenuated the triacylglycerol (TAG) accumulation caused by nonesterified fatty acids (NEFA). The cells were divided into 3 groups as follows: (1) control group, (2) Ad-GFP group (cells were infected with empty adenovirus vector for $48 \mathrm{~h}$ and treated with $1.2 \mathrm{mM}$ NEFA and $2 \%$ BSA for $24 \mathrm{~h}$ ), and (3) Ad-shPLIN5 + $1.2 \mathrm{~m} M$ NEFA group (transfected with PLIN5 knockdown adenovirus for $48 \mathrm{~h}$ and then treated with $1.2 \mathrm{mM}$ NEFA and $2 \%$ BSA for $24 \mathrm{~h}$ ). (A) Western blot analysis of PLIN5, sterol regulatory element-binding protein 1 (SREBP-1), fatty acid synthase (FAS), acetyl-coA carboxylase 1 (ACC1), diacylglycerol acyltransferase 1 (DGAT1), and diacylglycerol acyltransferase 2 (DGAT2). (B) Relative protein expression levels of PLIN5, SREBP-1, FAS, ACC1, DGAT1, and DGAT2. (C) Relative mRNA expression levels of PLIN5, SREBP-1, FAS, ACC1, DGAT1, and DGAT2. (D) The TAG content in hepatocytes. (E) Representative Oil Red O staining in hepatocytes; scale bar $=100 \mu \mathrm{m}$. (F) Western blot analysis of microsomal triglyceride transfer protein (MTP), apolipoprotein B100 (ApoB100), and apolipoprotein E (ApoE). (G) Relative protein expression levels of MTP, ApoB100, and ApoE. (H) Relative mRNA expression levels of MTP, ApoB100, and ApoE. (I) Very low density lipoprotein apolipoprotein B (VLDL-ApoB) content in supernatant. Comparisons among groups were calculated using a 1-way ANOVA with subsequent Bonferroni correction. The data presented are the mean \pm SEM. ${ }^{*} P<0.05,{ }^{* *} P<0.01$ compared with the $1.2 \mathrm{~m} M$ NEFA group. 
firm that both increase of lipid synthesis and decrease of VLDL assembly are involved in the development of hepatic steatosis in dairy cows.

The family of LD coat proteins known as perilipins has emerged as being essential in regulating fatty acid storage and release from LD (Ramos et al., 2016). The perilipin family of LD-associated proteins comprises 5 members (PLIN1 through PLIN5; Miura et al., 2002), with perilipin 1, perilipin 2 , and perilipin 3 being expressed in liver under normal conditions (Straub et al., 2008). The protein PLIN5 has been detected in mouse and human liver (Dalen et al., 2007; Li et al., 2012) and in periparturient cow liver (Loor, 2010). Furthermore, in humans with steatosis and obese $o b / o b$ mice, the protein and mRNA abundance of PLIN5 in liver is markedly increased, indicating that PLIN5 expression is most likely correlated with the development of hepatic steatosis (Wang et al., 2015). Thus, the fact that we detected a marked upregulation of PLIN5 protein abundance in the LD in cows with fatty liver strongly suggests its involvement in the induction of hepatic steatosis in dairy cows as in nonruminants.

Studies in rodents have revealed that PLIN5 contributes to the regulation of lipid synthesis and TAG accumulation in liver (Wang et al., 2015; Gao et al., 2017). For instance, in primary murine hepatocytes, Langhi et al. (2014) found that overexpression of PLIN5 resulted in a significant increase in TAG level and LD size. In agreement with those data, overexpression of PLIN5 resulted in the formation of large $\mathrm{LD}$ and elevation of TAG concentrations in bovine hepatocytes. The present data confirm that PLIN5 plays a similar role in bovine liver in promoting LD formation. In addition, the data demonstrating that PLIN5 overexpression significantly upregulated the expression of SREBP-1, fatty acid de novo synthesis genes (FAS and ACC1), and TAG synthesis genes (DGAT1 and DGAT2) in bovine hepatocytes agree with previous work in nonruminants demonstrating a link between LD formation and biosynthesis of lipid (Martin and Parton, 2006). Thus, the increase in expression of lipid synthesis-related molecules induced by PLIN5 overexpression in bovine hepatocytes supports the positive association between the abundance of PLIN5 and the degree of hepatic steatosis in vivo.

Limited secretion of VLDL in dairy cows is strongly correlated with fatty liver (Katoh, 2002; Bobe et al., 2004). Hence, the decrease in VLDL-ApoB concentration in bovine hepatocyte supernatant from cultures overexpressing PLIN5 underscores a negative association with VLDL assembly and secretion. Although the exact mechanisms responsible for this negative association could not be discerned, the downregulation of MTP, ApoB100, and ApoE suggests that changes in transcription are involved. These together with our in vivo data indicate that high abundance of hepatic PLIN5 may further exacerbate the inherently low rate of synthesis and export of VLDL in dairy cows with fatty liver.

High levels of fatty acids are the pathological basis of fatty liver in cows, with the most dramatic elevations occurring at calving, when plasma concentrations are often $>1,000 \mu \mathrm{Eq} / \mathrm{L}$. In rodents, high concentrations of NEFA cause steatosis and alter hepatic lipid metabolic gene abundance (Jump et al., 2005). Those responses were confirmed in vitro by the upregulation of SREBP-1, fatty acid de novo synthesis genes (FAS and ACC1), and TAG synthesis genes (DGAT1 and DGAT2) and the downregulation of MTP, ApoB100, and ApoE when exogenous NEFA were incubated with hepatocytes. Thus, as in nonruminants, high concentrations of fatty acids disrupted lipid homeostasis in the liver of dairy cows, and it is notable that PLIN5 also partly mediated this biological process. Because knockdown of PLIN5 prevented the increase in TAG concentration (along with alterations in protein and mRNA abundance), we speculate that PLIN5 mediates in part the development of NEFA-induced fatty liver in dairy cows during early lactation.

\section{CONCLUSIONS}

In vivo and in vitro experiments indicated that NEFA induced PLIN5 expression, which promoted lipid synthesis and inhibited VLDL assembly, thereby inducing hepatic steatosis in dairy cows. Accordingly, PLIN5 appears to be required for the development of fatty liver, and its function in lipid metabolism has important implications for potential therapeutic applications in the field of periparturient cow management.

\section{ACKNOWLEDGMENTS}

This work was supported by the National Key Research and Development Program (Beijing, China; grant no. 2016YFD0501206 and 2016YFD0501007), the National Natural Science Foundation of China (Beijing, China; grant no. 31472247, 31572581, 31672621, and 31772810 ), and the Jilin Province Science Foundation for Youths (Changchun, China; grant no. 20160520063JH). The authors report no conflicts of interest.

\section{REFERENCES}

Ballard, F. J., O. H. Filsell, and I. G. Jarrett. 1972. Effects of carbohydrate availability on lipogenesis in sheep. Biochem. J. 126:193-200. 
Bernabucci, U., B. Ronchi, L. Basiricò, D. Pirazzi, F. Rueca, N. Lacetera, and A. Nardone. 2004. Abundance of mRNA of apolipoprotein B100, apolipoprotein E, and microsomal triglyceride transfer protein in liver from periparturient dairy cows. J. Dairy Sci. 87:2881-2888.

Bobe, G., J. W. Young, and D. C. Beitz. 2004. Invited review: Pathology, etiology, prevention, and treatment of fatty liver in dairy cows. J. Dairy Sci. 87:3105-3124.

Contreras, G. A., K. Thelen, S. E. Schmidt, C. Strieder-Barboza, C L. Preseault, W. Raphael, M. Kiupel, J. Caron, and A. L. Lock. 2016. Adipose tissue remodeling in late-lactation dairy cows during feed-restriction-induced negative energy balance. J. Dairy Sci. 99:10009-10021.

Dalen, K. T., T. Dahl, E. Holter, B. Arntsen, C. Londos, C. Sztalryd, and H. I. Nebb. 2007. LSDP5 is a PAT protein specifically expressed in fatty acid oxidizing tissues. Biochim. Biophys. Acta 1771:210-227.

Drackley, J. K. 1999. ADSA Foundation Scholar Award. Biology of dairy cows during the transition period: The final frontier? J. Dairy Sci. 82:2259-2273.

Du, X., L. Chen, D. Huang, Z. Peng, C. Zhao, Y. Zhang, Y. Zhu, Z. Wang, X. Li, and G. Liu. 2017. Elevated apoptosis in the liver of dairy cows with ketosis. Cell. Physiol. Biochem. 43:568-578.

Du, X., T. Shen, H. Wang, X. Qin, D. Xing, Q. Ye, Z. Shi, Z. Fang, Y. Zhu, Y. Yang, Z. Peng, C. Zhao, B. Lv, X. Li, G. Liu, and X. Li. 2018a. Adaptations of hepatic lipid metabolism and mitochondria in dairy cows with mild fatty liver. J. Dairy Sci. 101:9544-9558. https://doi.org/10.3168/jds.2018-14546.

Du, X., Y. Zhu, Z. Peng, Y. Cui, Q. Zhang, Z. Shi, Y. Guan, X. Sha, T. Shen, Y. Yang, X. Li, Z. Wang, X. Li, and G. Liu. 2018b. High concentrations of fatty acids and $\beta$-hydroxybutyrate impair the growth hormone-mediated hepatic JAK2-STAT5 pathway in clinically ketotic cows. J. Dairy Sci. 101:3476-3487.

Edmonson, A. J., I. J. Lean, L. D. Weaver, T. Farver, and G. Webster. 1989. A body condition scoring chart for Holstein dairy cows. J. Dairy Sci. 72:68-78.

Farke, C., H. H. Meyer, R. M. Bruckmaier, and C. Albrecht. 2008. Differential expression of $\mathrm{ABC}$ transporters and their regulatory genes during lactation and dry period in bovine mammary tissue. J. Dairy Res. 75:406-414.

Ferré, P., and F. Foufelle. 2010. Hepatic steatosis: A role for de novo lipogenesis and the transcription factor SREBP-1c. Diabetes Obes. Metab. 12(Suppl. 2):83-92.

Fry, M. M., B. Yao, C. Ríos, C. Wong, S. Mann, J. A. A. McArt, D. V. Nydam, F. A. Leal Yepes, L. Viesselmann, A. Geick, K. Goldin, A. Jordan, and E. Behling-Kelly. 2018. Diagnostic performance of cytology for assessment of hepatic lipid content in dairy cattle. J. Dairy Sci. 101:1379-1387.

Gao, X., Y. Nan, Y. Zhao, Y. Yuan, B. Ren, C. Sun, K. Cao, M. Yu, X. Feng, and J. Ye. 2017. Atorvastatin reduces lipid accumulation in the liver by activating protein kinase A-mediated phosphorylation of perilipin 5. Biochim. Biophys. Acta Mol. Cell Biol. Lipids 1862:1512-1519.

Goff, J. P., and R. L. Horst. 1997. Physiological changes at parturition and their relationship to metabolic disorders. J. Dairy Sci. 80:1260-1268

Gross, J., H. A. van Dorland, R. M. Bruckmaier, and F. J. Schwarz. 2011. Performance and metabolic profile of dairy cows during a lactational and deliberately induced negative energy balance with subsequent realimentation. J. Dairy Sci. 94:1820-1830.

Hippen, A. R., P. She, J. W. Young, D. C. Beitz, G. L. Lindberg, L. F. Richardson, and R. W. Tucker. 1999. Alleviation of fatty liver in dairy cows by 14-day intravenous infusions of glucagon. J. Dairy Sci. 82:1139-1152.

Hughes, J. P. 1962. A simplified instrument for obtaining liver biopsies in cattle. Am. J. Vet. Res. 23:1111-1113.

Ingle, D. L., D. E. Bauman, and U. S. Garrigus. 1972. Lipogenesis in the ruminant: In vitro study of tissue sites, carbon source and reducing equivalent generation for fatty acid synthesis. J. Nutr. 102:609-616
Itabe, H., T. Yamaguchi, S. Nimura, and N. Sasabe. 2017. Perilipins: A diversity of intracellular lipid droplet proteins. Lipids Health Dis. $16: 83$

Jorritsma, R., H. Jorritsma, Y. H. Schukken, P. C. Bartlett, T. Wensing, and G. H. Wentink. 2001. Prevalence and indicators of post partum fatty infiltration of the liver in nine commercial dairy herds in the Netherlands. Livest. Prod. Sci. 68:53-60.

Jorritsma, R., H. Jorritsma, Y. H. Schukken, and G. H. Wentink. 2000. Relationships between fatty liver and fertility and some periparturient diseases in commercial Dutch dairy herds. Theriogenology 54:1065-1074.

Jump, D. B., D. Botolin, Y. Wang, J. Xu, B. Christian, and O. Demeure. 2005. Fatty acid regulation of hepatic gene transcription. J. Nutr. 135:2503-2506.

Katoh, N. 2002. Relevance of apolipoproteins in the development of fatty liver and fatty liver-related peripartum diseases in dairy cows. J. Vet. Med. Sci. 64:293-307.

Khan, M. J., C. B. Jacometo, D. E. Graugnard, M. N. Corrêa, E. Schmitt, F. Cardoso, and J. J. Loor. 2014. Overfeeding dairy cattle during late-pregnancy alters hepatic PPAR $\alpha$-regulated pathways including hepatokines: Impact on metabolism and peripheral insulin sensitivity. Gene Regul. Syst. Bio. 8:97-111.

Kimmel, A. R., D. L. Brasaemle, M. McAndrews-Hill, C. Sztalryd, and C. Londos. 2010. Adoption of PERILIPIN as a unifying nomenclature for the mammalian PAT-family of intracellular lipid storage droplet proteins. J. Lipid Res. 51:468-471.

Kleppe, B. B., R. J. Aiello, R. R. Grummer, and L. E. Armentano. 1988. Triglyceride accumulation and very low density lipoprotein secretion by rat and goat hepatocytes in vitro. J. Dairy Sci. 71:1813-1822

Langhi, C., T. J. Marquart, R. M. Allen, and A. Baldán. 2014. Perilipin- 5 is regulated by statins and controls triglyceride contents in the hepatocyte. J. Hepatol. 61:358-365.

Li, H., Y. Song, L. J. Zhang, Y. Gu, F. F. Li, S. Y. Pan, L. N. Jiang, F. Liu, J. Ye, and Q. Li. 2012. LSDP5 enhances triglyceride storage in hepatocytes by influencing lipolysis and fatty acid $\beta$-oxidation of lipid droplets. PLoS One 7:e36712.

Li, X., W. Huang, J. Gu, X. Du, L. Lei, X. Yuan, G. Sun, Z. Wang, X. Li, and G. Liu. 2015. SREBP-1c overactivates ROS-mediated hepatic NF- $\kappa B$ inflammatory pathway in dairy cows with fatty liver. Cell. Signal. 27:2099-2109.

Li, X., Y. Li, W. Yang, C. Xiao, S. Fu, Q. Deng, H. Ding, Z. Wang, G. Liu, and X. Li. 2014. SREBP-1c overexpression induces triglycerides accumulation through increasing lipid synthesis and decreasing lipid oxidation and VLDL assembly in bovine hepatocytes. J. Steroid Biochem. Mol. Biol. 143:174-182.

Loor, J. J. 2010. Genomics of metabolic adaptations in the peripartal cow. Animal 4:1110-1139.

Marcos, E., A. Mazur, P. Cardot, and Y. Rayssiguier. 1990. Serum apolipoprotein B and A-I and naturally occurring fatty liver in dairy cows. Lipids 25:575-577.

Martin, S., and R. G. Parton. 2006. Lipid droplets: A unified view of a dynamic organelle. Nat. Rev. Mol. Cell Biol. 7:373-378.

Miura, S., J. W. Gan, J. Brzostowski, M. J. Parisi, C. J. Schultz, C. Londos, B. Oliver, and A. R. Kimmel. 2002. Functional conservation for lipid storage droplet association among Perilipin, ADRP, and TIP47 (PAT)-related proteins in mammals, Drosophila, and Dictyostelium. J. Biol. Chem. 277:32253-32257.

Parker, J. E., and E. M. Gaughan. 1988. Partial hepatic resection for treatment of a single liver abscess in a dairy heifer. Vet. Surg. 17:87-89.

Pullen, D. L., J. S. Liesman, and R. S. Emery. 1990. A species comparison of liver slice synthesis and secretion of triacylglycerol from nonesterified fatty acids in media. J. Anim. Sci. 68:1395-1399.

Ramos, S. V., P. C. Turnbull, and R. E. MacPherson. 2016. Adipose tissue depot specific differences of PLIN protein content in endurance trained rats. Adipocyte 5:212-223.

Sevinc, M., A. Basoglu, and H. Guzelbektas. 2003. Lipid and lipoprotein levels in dairy cows with fatty liver. Turk. J. Vet. Anim. Sci $27: 295-299$. 
Straub, B. K., P. Stoeffel, H. Heid, R. Zimbelmann, and P. Schirmacher. 2008. Differential pattern of lipid droplet-associated proteins and de novo perilipin expression in hepatocyte steatogenesis. Hepatology 47:1936-1946.

Sun, X., X. Yuan, L. Chen, T. Wang, Z. Wang, G. Sun, X. Li, X. $\mathrm{Li}$, and G. Liu. 2017. Histamine induces bovine rumen epithelial cell inflammatory response via NF- $\kappa$ B pathway. Cell. Physiol. Biochem. 42:1109-1119.

Uchida, E., N. Katoh, and K. Takahashi. 1992. Induction of fatty liver in cows by ethionine administration and concomitant decreases of serum apolipoproteins B-100 and A-I concentrations. Am. J. Vet. Res. 53:2035-2042.

Wakil, S. J. 1989. Fatty acid synthase, a proficient multifunctional enzyme. Biochemistry 28:4523-4530.

Wang, C., Y. Zhao, X. Gao, L. Li, Y. Yuan, F. Liu, L. Zhang, J. Wu, P. Hu, X. Zhang, Y. Gu, Y. Xu, Z. Wang, Z. Li, H. Zhang, and J. Ye. 2015. Perilipin 5 improves hepatic lipotoxicity by inhibiting lipolysis. Hepatology 61:870-882.
Wathes, D. C., Z. Cheng, M. A. Fenwick, R. Fitzpatrick, and J. Patton. 2011. Influence of energy balance on the somatotrophic axis and matrix metalloproteinase expression in the endometrium of the postpartum dairy cow. Reproduction 141:269-281.

Wetterau, J. R., M. C. M. Lin, and H. Jamil. 1997. Microsomal triglyceride transfer protein. Biochim. Biophys. Acta 1345:136-150.

Wilfling, F., H. Wang, J. T. Haas, N. Krahmer, T. J. Gould, A. Uchida, J. X. Cheng, M. Graham, R. Christiano, F. Fröhlich, X. Liu, K. K. Buhman, R. A. Coleman, J. Bewersdorf, R. V. Jr. Farese, and T. C. Walther. 2013. Triacylglycerol synthesis enzymes mediate lipid droplet growth by relocalizing from the ER to lipid droplets. Dev. Cell 24:384-399.

Zulewski, H., R. Ninnis, A. R. Miserez, M. W. Baumstark, and U. Keller. 1998. VLDL and IDL apolipoprotein B-100 kinetics in familial hypercholesterolemia due to impaired LDL receptor function or to defective apolipoprotein B-100. J. Lipid Res. 39:380-387. 